\title{
Making injury prevention a top social issue: the Canadian Injury Prevention Foundation
}

\author{
Catherine Kingdon
}

Dr Robert Conn established the Canadian Injury Prevention Foundation in 1991, after training as a children's heart surgeon. At that time, he began to question the impact of his career as a surgeon. His job required 'harvesting' the hearts of people who were fatally injured. Although these hearts were destined for transplantation, Dr Conn couldn't ignore the fact that the donors were predominantly teens who died of preventable injuries. 'As time went on, I began to realize that this was insane. So many of these individuals were dying needlessly'. He became convinced that someone 'had to lay down the scalpel and come out into the community'.

Accepting this new challenge, Dr Conn began to study injuries and prevention. What he discovered was astounding. Injuries are the leading cause of death for people between the ages of 1 and 44 years in Canada. That means there are more years of productive life lost from injuries than from cancer, heart attacks, and strokes combined. Teens rank as the largest group to suffer the consequences of injuries: seven out of every 10 who die each year, die as a result of injuries. The financial burden to Canadian taxpayers is staggering: $\$ 13.2$ billion is spent annually treating those who are injured.

'Whenever we face something that results in so many deaths, such as meningitis, we call it an epidemic and take immediate action', says $\mathrm{Dr}$ Conn. 'Yet, we've conditioned ourselves to believe that an 'accident' is unavoidable. This is reflected in our language and attitudes. When we refer to car "accidents", boating "accidents", and skiing "accidents", we say "what a terrible tragedy", then we continue on as before. But, nothing could be further from the truth. We need to eliminate conditioning words like "accidents" and respond to these things for what they are - preventable events'.

'As a society we've developed a fatalistic attitude, and as a result we think there is nothing we can do to prevent injuries from happening. Changing this attitude is our primary goal', Dr Conn says. 'Injury prevention is about managing risk and getting people to look at life as a spectrum of risks, and that it is OK to take smart risks. But, we know that we won't change people's attitudes by lecturing. Instead, we're taking a dynamic approach to injury prevention'.

The first program developed nationally by the foundation is HEROES, a travelling road show about smart risks and personal choices. It is one hour long, and is dedicated to raising injury awareness and prevention potential among teenagers. The program encourages teens to make the choices that will minimize the likelihood of injury. HEROES also motivates people to develop coalitions that continue to advocate prevention in their community.

The HEROES program uses a wide screen, multi-image presentation with a high quality quadraphonic sound system and gigantic images created by computer controlled projectors. During the program, a young injury survivor talks to teenagers about how the injury has affected his or her life. As well, a teenager from the community hosting HEROES outlines the positive choices that can be made to reduce the risks of being injured.

Every element of the HEROES program, from the date when the program is booked to visit a community, through to the closing portion of the presentation, is designed to bring together teens and adults. Community leaders involved in public health, education, local associations and clubs, work for months to organize the logistics and promotion. Long before the HEROES truck rolls in, transporting the $6000 \mathrm{lbs}$ of equipment needed to mount the show, local students volunteer as members of the stage crew. This group becomes intimately involved with the delivery of the program, and often are the 'marketing agents' of HEROES when they return to their classrooms to promote the program. Several teens are chosen as teen presenters, who deliver the core HEROES messages to their peers. HEROES says that risk taking is an integral part of living, and that to stop taking risks would 'just be another kind of paralysis'. However, the program stresses five simple choices everyone can make. They are: Buckle Up, Drive Sober, Wear the Gear, Look First, and Get Trained.

April Bond, a high school graduate, and a two time teen presenter, attributes HEROES success to the fact the program emphasizes choice and smart risk. 'They're not saying don't take risks. It's not just another lecture. the message is: do it for yourself'. HEROES hit home for April, who knows that most teens like to think they're invincible. 'The program shows everyone that they're not, and they have a choice. It makes them more aware'.

So far, one unit has traveled across Canada bringing the unique HEROES message to more than 250000 people. In some centres, HEROES is a catalyst for the development of 
injury prevention coalitions. These groups have expanded their membership to host citywide HEROES festivals that may involve the entire community. To date nine communities across Canada have hosted festivals to promote risk management through innovative displays and partnerships. In Kelowna, British Columbia the foundation encouraged the creation of a diverse community coalition with support from the school board, hospital, and the police and fire departments, and from sporting groups such as snowmobiling and motorcycle clubs, who demonstrated their risk-management skills. Festival displays focused on how to 'risk it right', and the mayor declared it Injury Prevention Week. The HEROES festival became the best attended event in the city's history.

Royal Insurance Canada, General Motors of Canada, Canadian Forces Air Command, Bell Canada, and Bell Mobility are corporate sponsors of the program, providing support to bring HEROES to communities across Canada. Local Royal Insurance brokers and General Motors dealers may join an organizing coalition to assist with the logistical arrangements and promotion.

In addition to delivering HEROES, the foundation developed a unique communications campaign called 'The Stupid Line'. Comprising print, $\mathrm{TV}$, and radio announcements, The Stupid Line uses language to shift people's attitudes towards injuries. To create The Stupid Line, the foundation began to evaluate how people perceive and take risks. The conclusion was that for everyone there is a spectrum of risk. Ranging from risks that are too great to take, such as lighting a match at a gas station, or jumping in front of a moving train, to risks that seem so small, we don't perceive them to be a risk. The latter include riding on a elevator, or crossing the street. For everyone though, there is a line in the middle which separates smart risk from stupid risk. People consciously, or unconsciously, choose where they will draw that line. For example, a person may always wear a seatbelt when driving on the highway, but choose to not wear one if they are driving in their neighborhood. That line of choice was coined The Stupid Line, and an entire communications campaign grew around it.

Response from teens, teachers, and parents has been positive. Most can relate to having a Stupid Line, and they like the fact that the campaign doesn't call anyone stupid. Teens, in particular, are open to peer pressure, and the language used in the campaign provides tools for them to deal more convincingly with their friends.

'A lot of people figure they're totally invincible', says Vivian Garcia, a quadriplegic. 'They go around and figure nothing will ever happen to them because they're young. It only happens to someone else. Well, it doesn't always happen to someone else. Sometimes it happens to you'. 